Meta

Journal des traducteurs

Translators' Journal

\title{
Teaching Medical Translation
}

\section{Judy Wakabayashi}

Volume 41, numéro 3, septembre 1996

URI : https://id.erudit.org/iderudit/004584ar

DOI : https://doi.org/10.7202/004584ar

Aller au sommaire du numéro

\section{Éditeur(s)}

Les Presses de l'Université de Montréal

ISSN

0026-0452 (imprimé)

1492-1421 (numérique)

Découvrir la revue

Citer cet article

Wakabayashi, J. (1996). Teaching Medical Translation. Meta, 41(3), 356-365. https://doi.org/10.7202/004584ar

\section{Résumé de l'article}

Le peu de connaissances médicales des étudiants et leur manque de familiarité avec la terminologie et la phraséologie médicales constituent les principaux obstacles de l'enseignement de la traduction médicale. On peut résoudre partiellement ces problèmes en initiant les étudiants aux termes clés relatifs à l'anatomie, aux diagnostics, aux symptômes, aux opérations, aux tests de laboratoires et aux procédures en clinique. En plus d'effectuer de nombreux exercices, les futurs traducteurs devront connaître les racines grecques et latines, les affixes et la combinatoire, les abréviations médicales courantes, la différence entre les termes populaires et les termes médicaux scientifiques, le style médical anglais et les standards des articles médicaux.
Ce document est protégé par la loi sur le droit d'auteur. L'utilisation des services d'Érudit (y compris la reproduction) est assujettie à sa politique d'utilisation que vous pouvez consulter en ligne.

https://apropos.erudit.org/fr/usagers/politique-dutilisation/ 


\title{
TEACHING MEDICAL TRANSLATION ${ }^{1}$
}

\author{
JUDY WAKABAYASHI \\ University of Queensland, Brisbane, Australia
}

\begin{abstract}
Résumé
Le peu de connaissances médicales des étudiants et leur manque de familiarité avec la terminologie et la phraséologie médicales constituent les principaux obstacles de l'enseignement de la traduction médicale. On peut résoudre partiellement ces problèmes en initiant les étudiants aux termes clés relatifs à l'anatomie, aux diagnostics, aux symptômes, aux opérations, aux tests de laboratoires et aux procédures en clinique. En plus d'effectuer de nombreux exercices, les futurs traducteurs devront connaître les racines grecques et latines, les affixes et la combinatoire, les abréviations médicales courantes, la différence entre les termes populaires et les termes médicaux scientifiques, le style médical anglais et les standards des articles médicaux.
\end{abstract}

\begin{abstract}
The main difficulties specific to medical translation are students' lack of medical knowledge and their unfamiliarity with medical terminology and phraseology. These difficulties can be partially overcome by a bilingual introduction to the key anatomical terms, diagnostic terms, symptomatic terms, operative terms, laboratory tests, and clinical procedures related to each of the body systems. Together with ample practice in actual translation, a medical translation course should also include information on useful resource materials; Latin and Greek roots, affixes and combining forms; common medical abbreviations; "lay" terms vs medical terms; medical English style; and the standard format of medical journal articles.
\end{abstract}

\section{INTRODUCTION}

Medical translation is one of the growth areas of translation, at least in the case of Japanese-English translation. To reflect this market reality, final-year students in the Master of Arts in Japanese Interpreting and Translating at the University of Queensland have a weekly two-hour class in medical translation during second semester. Few students have any medical training, and in just 12 weeks it is impossible to impart all the knowledge necessary to become a proficient medical translator. Much, however, can be done towards providing students with a sound foundation on which to build a future career as a medical translator.

Medical translation covers a range of genres, from health information brochures and articles on health in magazines for the general public to medical textbooks, instructions accompanying prescription drugs, and specialized articles in medical journals. The texts translated in our course are mostly articles in medical journals, as this is where the demands lies in the "real" world of Japanese-English translation. This is somewhat different from the types of health-related translation common in "community" languages.

The three main areas which present difficulty in medical translation are as follows:

1. Students' lack of medical knowledge;

2. Medical terminology;

3. Medical phraseology. 
It is these three areas which characterise the teaching of medical translation. In other respects, teaching medical translation is little different from teaching translation in any other technical field, and conventional teaching techniques can be used. The main goal in teaching these three areas is to help students perceive the systems underlying both medical terminology and the body of medical knowledge.

\section{TEACHING THE BACKGROUND KNOWLEDGE}

Specialized knowledge is without doubt a great asset to the translator, making it easier to go beyond the surface meaning. Although such knowledge is desirable, however, a lack of formal medical training is not necessarily an insurmountable obstacle to the budding medical translator. What is essential is not a medical degree, but a broad understanding of the fundamentals and a knowledge of how to acquire, in the most efficient manner, an understanding of other elements as and when necessary.

Towards this end, the course at the University of Queensland adopts an approach whereby students are given an overview of the field of medicine through a systematic program that focuses on a different body system each week:

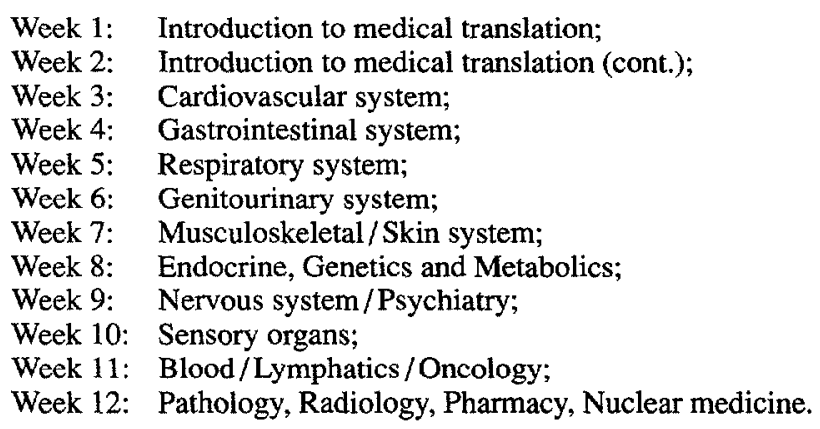

The first two weeks of the course are devoted to acquiring background knowledge that is applicable in all areas of medicine. The topics covered in the introduction include the following:

* Key reference works;

* The structure of medical terms-i.e. Latin and Greek roots prefixes, suffixes, combining forms and word-combining rules;

* Differences between British and American medical English;2

* Guidelines for pronouncing medical terms; 3

* The formation of the plural of medical terms; 4

* Medical faux amis; 5

* Medical abbreviations; $;$

* Common medical symbols;

* Planes of the body;

* Directional/positional terms; 8

* Conventions in medical English;

* The different types of drug names (i.e. the chemical name, generic name, and proprietary name), and the use of capitalization with proprietary drug names;

* Medical euphemisms; 9

* Sub-medical vocabulary;

* Medical phraseology;

* Medical antonyms. ${ }^{10}$ 
At the beginning of the course students are given an annotated handout describing useful reference sources. These include monolingual and bilingual medical dictionaries, collections of abstracts, dictionaries of medical acronyms, sources for verifying drug names, and key references such as the Merck Index and Merck Manual. Students are also encouraged to familiarize themselves with Medline an on-line medical abstract service which is an invaluable resource.

I do not make specific suggestions each week as to what works would be useful for researching a specific translation passage. Finding suitable books and articles at this level is part of the research skills that students must acquire. Not only must they be able to find the information they need, but they must also learn to do this efficiently-i.e. obtain maximum results in the minimum time. Students are advised that in a real-world situation it is wise to request copies of any very recent references cited in the source text from the author or client, as it may be difficult to obtain such papers. Direct contact with the author also enables the translator to request the author's preferred equivalents of specialized terminology and to obtain any other necessary information- e.g. colour photos for checking the exact colours to which reference may be made. In a classroom situation, however, such content is usually impossible.

After the initial two-week introduction, each weekly class concentrates in a particular body system. As there is no time to impart detailed background knowledge in class time, handouts (usually about 10 pages long) are used to give an overview of each body system. Students are provided with the relevant handout when assigned the homework translation for the following week, which is a passage which deals with some aspect of that particular body system. Before commencing the translation at home, students read the handout, which covers the key anatomical terms, roots and affixes, diagnostic terms, symptomatic terms, operative terms, laboratory tests, clinical procedures and abbreviations related to that body system. Each English term is briefly defined, the Japanese equivalent is given, and bilingual illustrations are appended where possible to clarify the meaning of the terms.

To provide further background information, videos and slides borrowed from the Audiovisual Services section of the university library are occasionally shown in class. Finding suitable videos is difficult, however, as existing videos tend to be either too general (e.g. TV documentaries for the general public) or too narrow in scope (e.g. videos showing physicians how to diagnose a particular disease or how to carry out a particular procedure). Ideally, videos in both languages would be shown, but so far I have access only to English-language videos. In any case, there is generally not enough time to show videos in class, as the main emphasis is on discussion of the actual texts translated. The best that can be done is to apprise students of the existence of such audiovisual aids for individual viewing outside class time.

\section{TEACHING MEDICAL TERMINOLOGY}

The most obvious problem (though not necessarily the most difficult) in medical translation is the specialized terminology used. For students beginning medical translation, medical texts seem to contain a mass of highly-specialised terms with which students are not familiar even in their native language. Fortunately, there are several comprehensive bilingual medical dictionaries which contain most of the medical terms the translator will encounter. Nevertheless, looking up a dictionary to find out that tanseki sekkai means "cholelithotomy" may still leave the translator feeling insecure, because he or she does not know what the term means. It is then necessary to look up the meaning in a monolingual 
medical dictionary (again encountering many specialized terms which may do little to clarify the meaning).

An alternative is to analyze the meaning of the component elements. (In this connection, it is interesting to note that the meaning of Japanese medical terms is often more transparent than is the meaning of the English term, because each character carries a meaning.) A knowledge of the common Latin and Greek roots and affixes used to form medical terms is extremely helpful in analyzing the meaning of English medical terms, which generally consist of some or all of the following components:

Word root: This usually represents the organ of the body;

Prefix: $\quad$ (Not all words have a prefix);

Suffix; $\quad$ This describes the disease process or the operation;

Combining form: A vowel linking the root to the suffix or to another root.

For example, the word "cholelithotomy" can be analyzed into the following components:

$\begin{array}{ll}\text { chole: } & \text { gall bladder (root); } \\ \text { lith: } & \text { stone (root); }\end{array}$

otomy: incision into (suffix);

i.e. an incision into the gall bladder for the removal of stones.

Students should be made aware, however, that the meaning of a term does not always reflect the exact meaning of the individual components, so that such analysis is not always infallible. For example, "neuritis" does not mean "inflammation of the nerve" as one would expect from an analysis of the root and suffix but a "condition of the nerve." Similarly, although the suffix "ectasis" means "expansion and dilation," "atelectasis" means only "collapse of the lung." Despite such anomalies, a knowledge of the meaning of the main roots and affixes pertaining to each body system, together with a knowledge of their equivalents in the other language, is an invaluable tool for the medical translator. 11

Although most terms can be found in a medical dictionary, occasionally the translator is faced with the problem of finding equivalents for terms not listed in existing dictionaries. The basic techniques advocated here are as follows:

1. Make use of all the information provided within the text. Many Japanese medical articles not only have an English abstract, but also often have English captions to the figures and use some English terms within the article. For instance, the term shuuseki, used repeatedly in one text, was translated by the lay terms "concentration" or "accumulation" by the students, who failed to realise that shuuseki is the Japanese equivalent for the English word "uptake" which appeared elsewhere in the body of the text in the English phrase "differential uptake ratio." The references cited at the end of Japanese journal articles also usually contain references to papers written in English, many of which can be tracked down to provide an abundance of background information and appropriate terminology.

2. Use a reverse medical word finder. Unlike traditional dictionaries which list a term as the head word and then define it, word finders 12 work backwards from a definition of the term. This approach enables the "lay" translator to work from the concept, perhaps based on a literal translation of the Japanese back to the English medical term.

3. Read English texts on similar topics and pick out plausible terms that seem to fit the context.

With the latter two techniques, it is vital that students then cross-check the proposed equivalent in a monolingual English medical dictionary such as Stedman's, as well as in an English-Japanese medical dictionary. 
Students must also be warned of the potential dangers of using medical terms found in general dictionaries, as the terms and equivalents listed in non-specialized dictionaries are sometimes misleading or completely inaccurate.

Naturally, terminological problems in medical translation go beyond the question of mere "findability." Bilingual medical dictionaries are beset by all the limitations facing any bilingual dictionary, and there is no guarantee that finding an "equivalent" in the dictionary means that it will be appropriate in a particular context. Within the constraints operating in a short university course, however, it is difficult to go beyond the strategies outlined above to give students the in-depth medical knowledge necessary to make fine judgments on the appropriateness of terms in a particular context.

One trap when translating Japanese medical texts is that the semantic transparency of the characters used to form Japanese words means that often it is easy to come up with a direct translation that makes perfect "lay" sense but is not necessarily in accordance with proper medical usage. For instance, the characters of mukei sanpu literally translate as "women who have not experienced birth," but the correct term is "nulliparous women;" the phrase kekkan shoogai literally means "blood vessel disorders," but is better rendered as "vascular disorders" or "angiopathy;" sekkekkyuu seisei literally means "red blood cell formation," but the medical term is "erythropoiesis;" and tokuchooteki normally is translated as "characteristic," but in a medical context the term "pathognomonic" is often used instead. Although generally a failure to use the specialized term will not lead to mistranslation, it does mean that the translated text will lack the appropriate register.

As far as register is concerned, it is important to use different terms depending on the target readership-e.g. lay readers or readers with medical knowledge. Students must be made aware of the difference between sub-medical vocabulary ${ }^{13}$ and proper medical terminology. Below are some examples from Brunt (1987) of the differences between these two groups of vocabulary:

Lay term
bad kidneys / kidney trouble
birth
bleed
bug
bum
Caesars
down below
front passage
gut
housemaid's knee
number two
palpitations
pee
shingles
ticker
to be careful
tummy
waterworks
womb

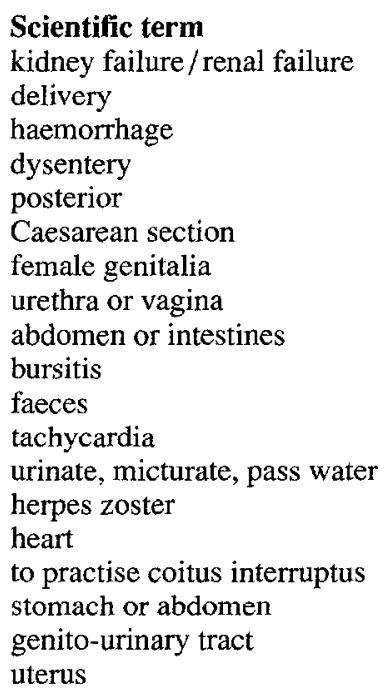

Of course, in some situations the lay term is the more appropriate of the two. What is important is for the translator to be aware of the difference between the two registers and to choose the appropriate term in a particular translation situation. 


\section{TEACHING MEDICAL PHRASEOLOGY}

Goodman and Edwards (1991: 26) claim that "Except for technical terms [...] medical English is not a special kind of English." I would disagree with this statement, in that it is not just the terms of art (which are essentially nouns) which distinguish medical texts from general texts, but also certain turns of phrase that are commonly used by medical writers instead of the everyday "lay" expression. For instance, a word which normally translates as "on the same side" (onajigawa no) becomes "ipsilateral" and its antonym hantaigawa no-normally rendered as "on the opposite side"-_becomes "contralateral." (Ironically, although the task facing students is to become familiar with the turns of phrase of medical English, nowadays in some medical circles there is a move towards plain English. This may eventually make the translator's task easier, but in the meantime students need to become familiar with the accepted phraseology of the profession.)

The traditional advice given to translators wishing to specialize in any field is to read widely so as to become familiar with the subject matter and, hopefully, to acquire the phraseology by "osmosis." Certainly, students should be encouraged to read medical texts as much as possible, but in view of the limited time available for acquiring this specialized knowledge in a one-semester course, a more focused approach is desirable.

Numerous books and articles on medical English have been published, but they tend to concentrate on the mechanics of preparing papers for medical journals or on teaching doctors how to improve their English writing skills. Such works are of limited relevance to the translator who has, presumably, good English writing skills but lacks familiarity with medical phraseology. What the translator requires is works that explain how to "sound" like a medical practitioner-i.e. how to make the move from lay English to medical English.

In this respect, the most useful book I have seen is Merne's Handbook of Medical English Usage (1989). Written by a lecturer in translation and aimed primarily at medical personnel who are not native speakers of English, this book is also useful for English native speakers with no medical background. It concentrates on expressions from general English that are used in a particular way in medical English and on the usage of common medical expressions. Over 2400 head words are listed alphabetically, accompanied by definitions, usage examples, antonyms, and hints on collocational and prepositional usage and plain English equivalents. The approach is descriptive rather than prescriptive, although the appendix lists certain expressions that should be avoided. Though a good portion of the book is irrelevant to the needs of native speakers of English, much of value can be culled from a careful reading.

To accustom students to the style and phraseology of medical English, I have prepared a handout (over 70 pages) based on relevant items from Merne's book which have been matched, where possible, with the Japanese expression 14 and any other usage information found in other reference works and style guides. Students are also advised to keep a record of such expressions found in their own background reading. Some sample items from the phraseology guide I have prepared are as follows:

busshitsu: an agent: a substance with a certain effect. e.g. a disease-causing agent $=$ a pathogenic agent $=$ a pathogen.

byooin: cause, pathogenesis, causative ([a]etiologic) factor (agent), cause of disease. The term "(a)etiology" is often used, but strictly speaking this refers to the "science of the causes of the disease," not the cause itself (Goodman and Edwards 1991: 41).

byooreki: case history, history: a record of a patient's medical background. Also anamnesis, but this term is hardly ever used. See also kioo[reki]. 
gappei suru: to complicate: to add new developments to a disease. e.g. ...is complicated by...; complications ensue; experience/encounter/have complications. A ni gappei suru $B$ : B complicating A.

kinki to sareru: to contraindicate: i.e. to advise against the use of a particular drug or treatment. e.g. to contraindicate surgery. Often used in the passive-e.g. the drug is strictly contraindicated. Contraindication for / to - e.g. no contraindication to surgery.

ryoohoo: regimen, treatment, course, regime of therapy, therapeutic approach, therapy. Prefer "treatment," "prescription" or "regimen" to "regime." "Regimen" is "best used to imply a change in the way of life." Another possibility is "scheme" (Goodman and Edwards 1991: 64).

byoorei: case. Many writers consider the use of "case" instead of "patient" to be inaccurate or unethical in scientific writing.

The emphasis is on explaining the meaning, providing at least one equivalent, listing any synonyms, antonyms or related terms, and demonstrating collocational usage. Translators would have no difficulty rendering the above expressions into everyday English, as they are not specialized terms, but the accepted phraseology is often far removed from the lay equivalent.

Another means of familiarizing students with English medical phraseology is to devise writing exercises (solely in English, the target language) where students fill in the blanks with an appropriate word or expression. Initially this can take the form of multiple choice exercises, but later students can be required to produce an appropriate expression autonomously. So as to save class time, this form of exercise could be incorporated into a self-study text on medical phraseology.

Another part of the teacher's job is to inform students of the conventions of medical English-e.g. the fact that quotation marks are used with proprietary names but not with generic drug names; the fact that for measurements of length and height the metre and the millimetre are used in preference to the centimetre $(e . g .37 \mathrm{~mm}$ rather than $3.7 \mathrm{~cm} ; 1.54 \mathrm{~m}$ rather than $154 \mathrm{~cm}$ ) (Newmark 1976); and the fact that in medical style even numbers under ten are often written as figures (e.g. 2 years, 8 weeks). Another convention is the tendency to use the prepositions "at" and "on" 15 instead of "at the time of" or "when"- e.g. at surgery, at laparatomy, at 10 years of age; on admission, on microscopy, on renal biopsy, on cytologic examination.

The structure of English medical articles is also highly conventionalized with the typical structure consisting of the following sections:

Introduction;

Materials;

Methods (or Patients and Methods or Subjects and Methods: sometimes Materials and Methods are collated in one section);

Results (or Observations);

Discussion.

By and large, the structure of medical journal articles in Japan is similar to this, so Japanese medical papers can be translated with very little adjustment required at the text level. Within each section there are also certain conventions, ${ }^{16}$ as well as conventional expressions that occur repeatedly with only minor variations, and students can benefit from being made aware of the overall textual structure of the medical papers and of the typical expressions used in each section. 


\section{CONCLUSIONS}

The specialized terminology and unfamiliar subject of medical papers can daunt students and distract them from the sense, leading to a failure to grasp the sentence structure and logic. Practice in reading through unknown terms to find the underlying linguistic structures and semantic relationships is essential. Towards this end, exercises in block analysis (Gile 1987) are useful in that they help students to break down the structure into the main components-subject, object, etc.-and to focus on the relationships between the different elements of the sentence.

Much of the discussion above has focused on a somewhat passive approach to teaching medical translation-i.e. an approach whereby the teacher provides students with handouts, exercises and videos in an attempt to improve their medical knowledge and their grasp of medical terminology and phraseology. These passive aids do indeed play an important role, but in our course this learning takes place largely outside the classroom after the first two introductory weeks, as students work through the handouts and exercises at home. In the classroom the overwhelming focus remains on active peer group discussion of actual passages translated for homework.

The medical translation course at the University of Queensland is still in the developmental stage, and no doubt changes and refinements will be made in future years. I hope, however, to have demonstrated here that there are a number of aspects of medical translation that can be taught systematically, thus alleviating the burden on students. The emphasis is not on imparting vast amounts of specialized medical knowledge, but on providing students with the tools for tackling medical translation so that they lose their fear of medical texts while retaining a "healthy" respect for the difficulties of medical translation.

Notes

1. I would like to acknowledge my debt to Janette Hadden, coordinator of the Medical Terminology Course at the Princess Alexandra Hospital, Brisbane.

2. Japanese/English medical dictionaries generally follow American spelling. Without a knowledge of the differences between British and American spelling, the Japanese-English translator may not be able to find a term when back-checking in an English-Japanese dictionary. Taber's Cyclopaedic Medical Dictionary (Thomas 1989) is recommended for checking British spelling. The main differences between British and American spelling in the field of medicine are the silent " $\mathrm{a}$ " or " $\mathrm{o}$ " preceding an " $\mathrm{e}$ " in British spelling.

British spelling: ae (e.g. aetiology, faeces, haematology, paediatrics, phaechromocytoma);

American spelling: e (e.g. etiology, feces, hematology, pediatric, pheochromocytoma);

British spelling: oe (e.g. hydrocoele, oedema, oesophagus);

American spelling: e (e.g. hydrocele, edema, esophagus);

British spelling: ou (e.g. tumour);

American spelling: o (e.g. tumor).

In some cases, the word itself may differ between American and British usage:

U.K.

anaesthetist

U.S.

to admit (to hospital)

dilatation

anesthesiologis

normality

doctor's surgery

theatre

to hospitalize

dilation

normalcy

doctor's office

(operating) theater

Students in our course are encouraged to follow British usage, but either usage is accepted as long as it is consistent.

3. Although correct pronunciation is not essential for the translator, the inability to pronounce a term increases the psychological difficulty of medical translation, so it is advisable to introduce students to guidelines for pronouncing medical terms.

4. Words ending in "is": Drop the "is" and add "es" e.g. epiphysis: epiphyses.

Words ending in "um": Drop the "um" and add "a" $e$.g. diverticulum: diverticula.

Words ending in "us": Drop the "us" and add "i" e.g. bronchus: bronchi (exceptions: viruses, sinuses). 
Words ending in "a": add "e" e.g. bulla: bullae.

Words ending in "ix" or "ex": drop the "ix" or "ex" and add "ices" e.g. varix: varices.

Words ending in "oma": add " $\mathrm{s}$ " or "ta" e.g. adenoma: adenomas or adenomata.

5. For example, ileum vs ilum and perineal vs peritoneal.

6. Some sources of information on medical abbreviation are as follows:

Dictionary of Biomedical Acronyms and Abbreviations (Dupayrat 1984)

Dictionary of Abbreviations in Medical Science (Heiser 1989)

Dictionary of Medical Acronyms and Abbreviations (Jablonski 1987)

7. Frontal or coronal; sagital or median; midsagital; and transverse.

8. Posterior, anterior, central, medial, lateral, superficial, deep, proximal, distal, supine, prone, superior, and

inferior. Also the various combinatory forms based on these terms, such as anterioinferior and posterolateral.

9. Students are taught to avoid such euphemisms as "expire," "pass away" or "succumb" instead of "die,"

"sacrifice" instead of "kill," and "fatality" or "mortality" instead of "death."

10. The following are a few examples of common antonyms in medical English (based on Merne 1989):

active

active drug

adverse effect

inactive; in remission

ambulatory patients

placebo

beneficial effect

chronic

bedridden patients

clinical studies

acute

research studies, pathological

or laboratory findings

community care

concentrate

hospital inpatient care

congenital; inborn

dilute

acquired

decrement

increment

free; unboundbound

immunocompetent

immunosuppressed

induced abortion

spontaneous abortion

study group

control group

surgery consultation

to contract (a muscle)

domiciliary consultation

to contract (one's chest)

to relax

to expand

11. There is a programmed self-study test on the terminology of medical English that is useful for native speakers of English who are studying Japanese-English medical translation. This is the Japanese translation of Smith and Davis (1982), which focuses heavily on understanding medical terms through the component roots and affixes.

12. Two useful medical word finders are the Medical Word Finder: A Reverse Medical Dictionary (Hamilton and Guidos 1987) and the Attorney's Dictionary of Medicine and Word Finder (Schmidt 1962). Volume 4 of the Attorney's Dictionary of Medicine and Word Finder contains a Reversicon where the meanings are listed alphabetically and placed before the terms they define. (The other volumes of the Attorney's Dictionary are also useful. They presuppose no medical knowledge on the part of the reader, and explain the terms in language that is comprehensible to the non-medically trained translator. Terms are listed under the term which is most likely not to be known to the user-e.g. "external carotid artery" is listed under "carotid" on the assumption that even lay readers understand "external" and "artery." The dictionary also contains examples of usage, illustrations, and clues to families of medical terms.)

13. Brunt (1987) defines sub-medical vocabulary as vocabulary "which is neither specialized nor highly colloquial and which is normally employed by patients when talking to doctors and which must be understood by doctors and also used by them if they wish to be understood by (less educated) patients."

14. Since bilingual medical dictionaries focus almost exclusively on terminology rather than phraseology, the source for most of the Japanese equivalents was Kobayashi (1991), which emphasizes usage rather than terminology. Although this book provides much valuable information, it needs to be used with care, as the Japanese translations are often extremely literal or simply incorrect. Another useful source is Ebizuka (1988).

15. The Japanese equivalents are the character $j i-e . g$. kaifukuji: at laparotomy; 10 sai no toki ni: at 10 years of age- and the particle de-e.g. kenbikyoo kensa de: on microscopy; saibooshin de: on cytologic examination.

16. For example, Goodman and Edwards $(1991: 28)$ note that the last sentence or paragraph of the introduction should state what the author was trying to do.

\section{REFERENCES}

BERKOW, R. and A. J. FLETCHER (1992): The Merck Manual of Diagnosis and Therapy, 16th ed., Rahway, N.J., Merck. 
BRUNT, R. J. (1987): "My Waterworks are Playing me up Something Chronic: The Description of the English of Medicine and Some Didactic Implications", W. Lorscher and R. Schulze (Eds.), Perspectives on Language in Performance, Tübingen, Gunter Narr, pp. 434-440.

BUDAVARI, S. (Ed.) (1989): The Merck Index; An Encyclopedia of Chemicals, Drugs and Biologicals, Rahway, N.J., Merck.

DUPAYRAT, J. (1984): Dictionary of Biomedical Acronyms and Abbreviations, New York, Chichester, Wiley. EBIZUKA, H. (1988): Nichiei Igaku Hyoogen Jiten, Tokyo, Aiikusha.

GILE, D. (1987): “The Block Analysis Method", JAT Bulletin, 32, pp. 19-21.

GOODMAN, N. W. and M. B. EDWARDS (1991): Medical Writing: A Prescription for Clarity, Cambridge, Cambridge University Press.

HAMILTON, B. and B. GUIDOS (1987): Medical Word Finder: A Reverse Medical Dictionary, New York, Neal-Schuman.

HEISER, R. (1989): Dictionary of Abbreviations in Medical Sciences, Berlin, Springer.

JABLONSKI, S. (1987): Dictionary of Medical Acronyms and Abbreviations, Philadelphia, Hanley and Belfus.

KOBAYASHI, M. (1991): Igaku eigo kanyoo hyoogenshuu, Tokyo, Bunkoodoo.

MERNE, S. (1989): Handbook of Medical English Usage, Oxford, Heinemann Professional Publishing.

NEWMARK, P. (1978): "A Layman's Approach to Medical Translation (Part 1)", The Incorporated Linguist, 15-2, pp. 41-47.

SCHMIDT, J. E. (1962): Attorney's Dictionary of Medicine and Word Finder, New York, Bender.

SMITH, G. L. and P. E. DAVIS (1982): Puroguramu gakushuu ni yoru igaku yoogo no manabikata, Translated by T. Urata, Tokyo, Igaku Shoin.

Stedman's Medical Dictionary (1982): 24th ed., Baltimore, Williams and Wilkins.

THOMAS, C. (Ed.) (1989): Taber's Cyclopedic Medical Dictionary, 16th ed., Philadelphia, F. A. Davis. 